\title{
Investigation of indoor propagation of WLAN signals
}

\author{
Mohammed S. Salim, Khalil H. Sayidmarie, Abdullah H. Aboud \\ Communication Engineering Department, College of Electronic Engineering, Ninevah University, Iraq
}

\begin{tabular}{l}
\hline \hline Article Info \\
\hline Article history: \\
Received Mar 20, 2019 \\
Revised May 26, 2019 \\
Accepted Jul 5, 2019 \\
\hline Keywords: \\
Indoor propagation \\
LOS \\
OLOS \\
Path loss exponent \\
WLAN \\
\hline
\end{tabular}

\begin{abstract}
The propagation of radio waves inside a typical university building is investigated by simulation and measurements. The Line of sight (LOS) and Obstructed Line of sight (OLOS) propagation scenarios were considered. The received power from a WLAN access point operating at $2.45 \mathrm{GHz}$ was determined from the simulations and measurements at various positions, orientations, and heights of the Tx and Rx antennas. The path loss exponents were estimated from the obtained simulation and measurement results of the received power variation with distance. The obtained path loss exponent values were found between 1.15-1.63 for LOS propagation and 2.14-2.55 for OLOS.
\end{abstract}

Copyright $(2019$ Institute of Advanced Engineering and Science. All rights reserved.

Corresponding Author:

Khalil H. Sayidmarie,

College of Electronic Engineering,

Ninevah University, Mosul, Iraq.

Email: kh.sayidmarie@gmail.com

\section{INTRODUCTION}

The need for using wireless communication systems has been an increasing focus of the attention of researchers and engineers [1]. Following an extensive series of measurements in Tokyo at frequencies up to $1290 \mathrm{MHz}$, Okumura et al., presented an empirical prediction model in 1968. This has been used for signal strength prediction in outdoor environments. For an easier application of Okumura model, Hata (in 1980) established empirical formulae to describe the graphical information published by Okumura [2]. After that, several indoor propagation models were proposed [3-7].

With the ever-increasing applications for wireless services, the attention is to provide a better prediction of wave propagation inside the buildings. This is because most of the mobile services are used indoors for most of the time. The successful design of wireless services requires sound knowledge about wave propagation in various indoor and outdoor environments. For a better location of the transmitter, it is vital to estimate the path loss inside the building, and how various objects influence the wave propagation. Thus the modern wireless services demand indoor propagation prediction. The propagation inside buildings is highly influenced by by many factors like type the of the building, the furniture and occupying persons [1].

A review of the path-loss prediction models for the indoor environment was presented in [8]. An approach to optimize the positions and numbers of access points to ensure good radio coverage in an indoor environment was presented in [9]. H. A. Obiedat, et al proposed an indoor path-loss prediction model using factors for wall correction for WLAN and 5G indoor network [10]. The obtained results from the proposed model were compared with other indoor models like one slope model, dual slope model, partitioned model, ITU model, COST231 and direct path model. The results were also compared with measurements and simulations (by Insite software) results.

This paper investigates the propagation within buildings by simulation and measurements. In the first part, theoretical analysis is presented, which includes simulations using the Insite ${ }^{\mathrm{TM}}$ software package (Remcom Company/ USA). The second part of the paper is the experimental measurements to assess the 
level of the signal received from an access point working at $2.45 \mathrm{GHz}$. From the simulation and measurement results, path loss exponent and RMSE values were calculated for various orientations and separations of the Tx and Rx at LOS and OLOS environments.

\section{THE LOG-DISTANCE PATH LOSS MODEL}

In the log-distance path-loss model the loss is assumed to vary exponentially with the distance between the transmitting and receiving antennas. The received power in $\mathrm{dB}$ is given by [7]:

$$
\overline{P_{r}}(d)=\overline{P_{r}}\left(d_{0}\right)+10 n \log (d / d o)
$$

Where $n$ is the path-loss exponent, $d$ is the separation in meters between Tx-Rx, and $d_{0}$ is a reference distance in meters. $P_{r}\left(\mathrm{~d}_{0}\right)$ is the received power at the reference distance $d_{0}$. The value of $d_{0}$ is selected such that it is larger than the far-field distance of the transmitting and receiving antennas, but still small relative to any practical distance between them (typically $d_{0}=1 \mathrm{~m}$ for indoor propagation).

\section{THE SIMULATION AND MEASUREMENT SCENARIOS}

For studying radio wave propagation in an indoor environment, the building of the Department of Communication Engineering/ Ninevah University was selected as the study region. The building consists of three similar floors. Each floor contains laboratories, classrooms, corridors, administrative rooms and W.C. as shown in Figure 1. Table 1 lists the specifications of the building used in the study. Three cases for three different Tx positions were investigated, where the received signal level across the floor was determined.

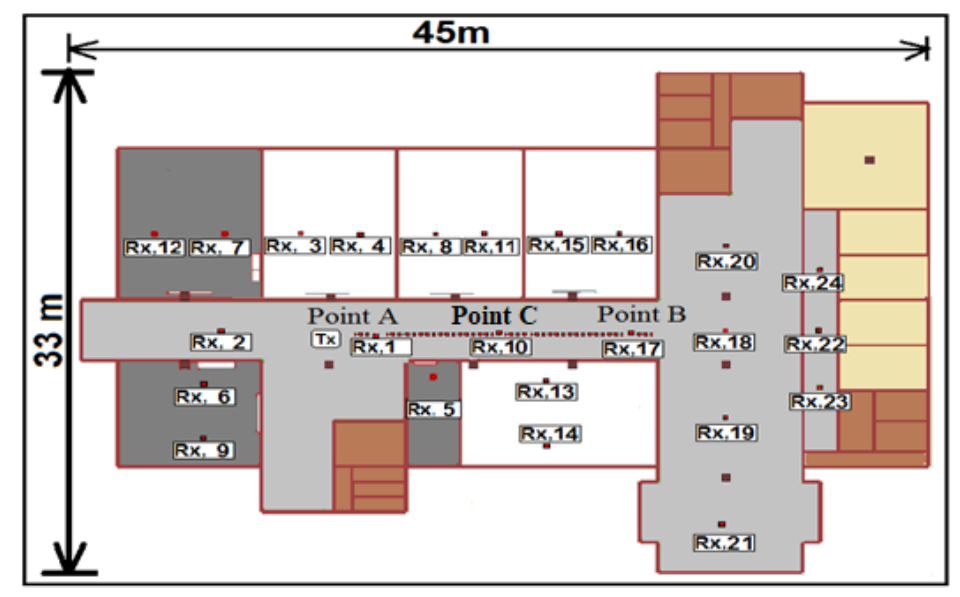

Figure 1. Geometry of the 1st floor of the Comm. Eng. Dept. building showing Tx and Rx positions

Table 1. Specifications of the Building of the Communication Eng. Dept./ Ninevah University

$\begin{array}{ll}\text { Height of the floor } & 4 \mathrm{~m} \\ \text { Thickness of walls } & 27 \mathrm{~cm} \\ \text { Materials of ceiling } & 1 \mathrm{~cm} \text { thick false ceiling panels }+50 \mathrm{~cm} \text { Air gap }+15 \mathrm{~cm} \text { reinforced concrete }+10 \mathrm{~cm} \text { Mosaic tiles } \\ \text { Material of floors } & \text { Concrete }+ \text { mosaic tiles }(30 \mathrm{~cm} * 30 \mathrm{~cm}) \\ \text { Material of walls } & \begin{array}{l}\text { Concrete blocks covered by plaster } \\ \left(\varepsilon_{\mathrm{r}}=4.44, \sigma=0.001\right)\end{array} \\ & \text { Plywood, Doors of Labs.; two parallel sheets of iron separated by } 3 \mathrm{~cm} \\ \text { Material of doors } & 4 \mathrm{~mm} \text { thick Glass, with iron bar grid of } 30 \mathrm{~cm} * 30 \mathrm{~cm} \\ \text { Material of windows } & \end{array}$

\subsection{Transmitter and Receiver Data}

A WLAN access point was chosen to be as the transmitter, which operates at $2.45 \mathrm{GHz}$. The antennas used for the transmitter and receiver were $\lambda / 4$ monopoles with a gain of $2 \mathrm{dBi}$. The transmitted power was kept constant at $4.5 \mathrm{dBm}$. The receiver antenna was placed at a height of $1.2 \mathrm{~m}$ above the ground (desktop height). 


\subsection{Computer Simulations}

The simulations of the radio wave propagation have been performed using the Wireless Insite ${ }^{\mathrm{TM}}$ software package (Remcom Company/ USA). The building has been reconstructed in the Insite Software according to its dimensions and types of materials. The Tx and Rx data specified in Section 4 were used. The ray-tracing model was used as the propagation model to predict the received power at various locations on the floor.

\section{EXPERIMENTAL MEASUREMENTS}

The measurements of the received power inside the building of the Dept. of Comm. Eng. was performed and compared with the results obtained from simulations. The surrounding environment was kept stationary during the data acquisition by preventing movements close to the transmitter and receiver. The transmitter used in the indoor propagation is an Access Point (D-link DWL 2100AP) as shown in Figure 2, which has the same specification mentioned above. A 3GHz spectrum analyzer (Agilent N9320B) was used as the receiver as shown in Figure 2. The antenna used for the receiver was a $\lambda / 4$ vertical monopole. The received power was measured by the spectrum analyzer and the results were recorded at sampling intervals of $30 \mathrm{~cm}$ along the propagation path under the study.

\section{ANALYSIS OF THE RESULTS}

This section presents the results (of simulation and measurements) for several studied scenarios.

\subsection{Received Power along the Corridor (LOS Cases)}

The received power along the $3 \mathrm{~m}$ wide corridor in the $1^{\text {st }}$ floor of the building was measured and compared with the simulation results for the three positions of the Tx (see Figure 1). The three cases are:

Case one: The Tx was placed at point $\mathrm{A}$ and the Rx was moved towards point $\mathrm{B}$.

Case two: The Tx was placed at point $\mathrm{C}$ and the $\mathrm{Rx}$ was moved towards point $\mathrm{B}$.

Case three: The Tx was placed at point $\mathrm{B}$ and the $\mathrm{Rx}$ was moved towards point $\mathrm{A}$.

Figure 3 shows comparisons between the results of the received power along the Tx-Rx path. Tables 2 and 3 show the calculated parameters of the received power results for the three cases. It is clear from Figure 3 and Tables 2, 3 that there is a substantial convergence in the mean values of the received power for the first and third cases that have almost the same number of data points and Tx-Rx separation $(15 \mathrm{~m})$. As regards the second case, the measurement and simulation were performed for a small range of $(7 \mathrm{~m})$, the mean values of the simulated and measured results are smaller than those for case 1 and case 2. This is because case 2 has a shorter path and thus a larger portion of the data is near the Tx that lead to higher average value. It can also be noticed that, in spite of the fluctuations in the simulation and measurement data the two fitted lines agree very well indicating similar trends.

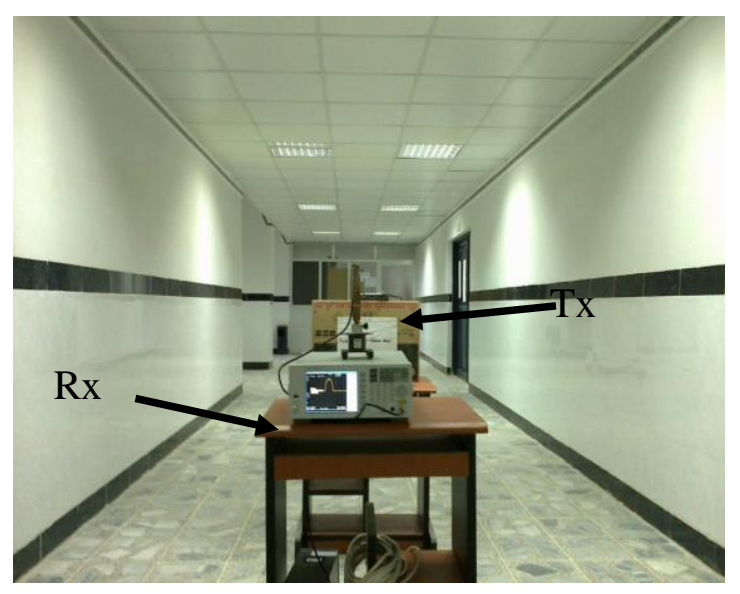

Figure 2. The spectrum analyzer used as the receiver, and the antenna on a trolley, which was moved along the corridor 


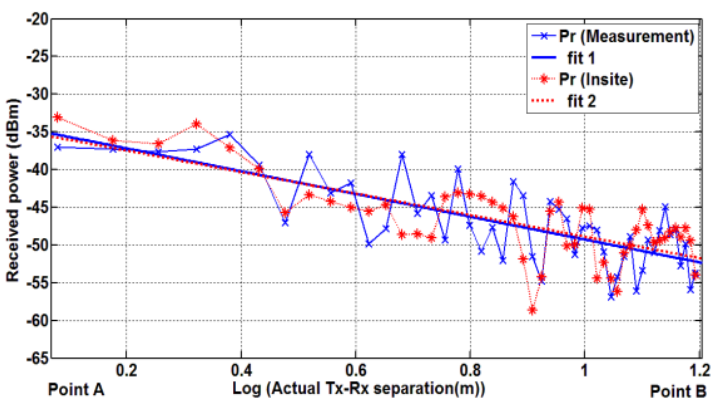

(a)

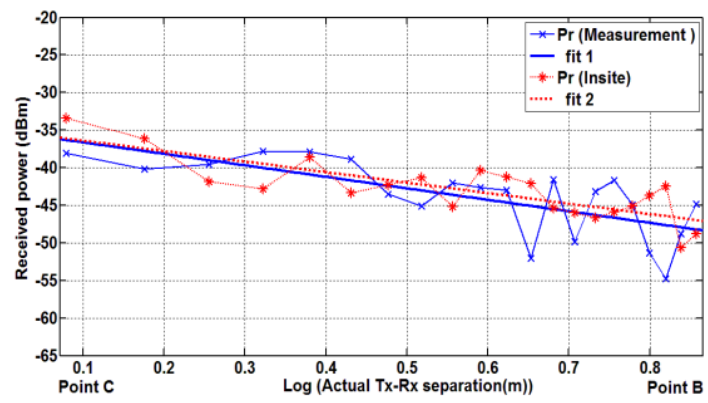

(b)

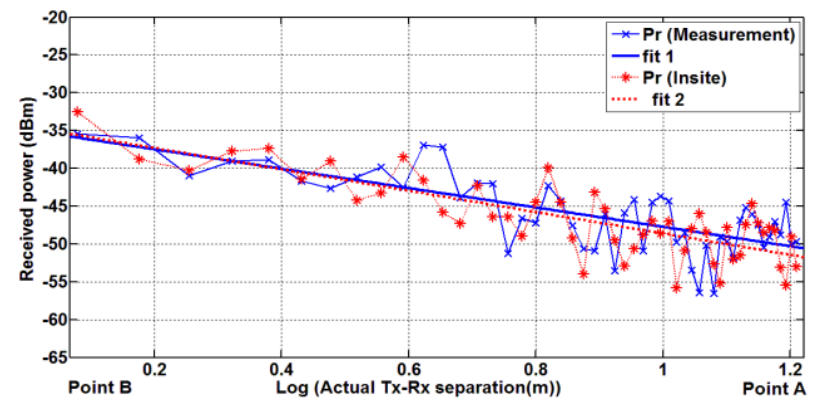

(c)

Figure 3. Comparison between the simulated and measured received power along the Tx-Rx path for; (a) $1^{\text {st }}$ case (Tx at point A), (b) $2^{\text {nd }}$ case (Tx at point C), (c) $3^{\text {rd }}$ case (Tx at point B)

Table 2. Mean Values of the Received Power for the Three Case

\begin{tabular}{llll}
\hline Case NO. & $\begin{array}{l}\text { Measurement } \\
\text { Mean }(\mathrm{dBm})\end{array}$ & $\begin{array}{l}\text { Simulation }(\text { Insite) } \\
\text { Mean }(\mathrm{dBm})\end{array}$ & $\begin{array}{l}\text { No. of data } \\
\text { points }\end{array}$ \\
\hline Case One & -46.96 & -46.7 & 49 \\
Case Two & -43.86 & -43.34 & 21 \\
Case Three & -45.96 & -46.65 & 51 \\
\hline
\end{tabular}

Table 3. Calculated Parameters of the Received Power Results for the Three Cases of the Tx Positions

\begin{tabular}{llllll}
\hline Case NO. & \multicolumn{2}{c}{ Measurement } & $\begin{array}{l}\text { Simulation } \\
\text { (Insite })\end{array}$ & $\begin{array}{l}\text { No. of data } \\
\text { points }\end{array}$ \\
& $\mathrm{n}$ & $\begin{array}{l}\text { RMSE } \\
(\mathrm{dB})\end{array}$ & $\mathrm{n}$ & $\begin{array}{l}\text { RMSE } \\
(\mathrm{dBm})\end{array}$ & \\
\hline Case One & 1.51 & 3.67 & 1.43 & 3.56 & 49 \\
Case Two & 1.53 & 3.57 & 1.4 & 2.96 & 21 \\
Case Three & 1.28 & 3.39 & 1.41 & 1.8 & 51 \\
\hline
\end{tabular}

\subsection{Effect of Height and Orientation of the Antenna on the Received Power}

To show the effect of changing the height and orientation of the Tx antenna on the received power, simulation and measurements were performed for two Tx antenna heights, $1.2 \mathrm{~m}$, and $2.5 \mathrm{~m}$ for both vertical and horizontal orientation. In these cases, the Tx and Rx antennas were kept parallel to each other thus always measuring the co-polarized component of the received field.

\subsubsection{Effect of Tx Antenna Height}

1) Vertical Antenna Orientation

Figure $4 \mathrm{a}, \mathrm{b}$ shows plots of the received power obtained from the simulation and measurement results for Tx heights of $1.2 \mathrm{~m}$ and $2.5 \mathrm{~m}$ for vertical orientation of the antennas. The receiving antenna was kept at a height of $1.2 \mathrm{~m}$. The calculated parameters of the received power are listed in Table 4 . The Figure 4 shows that the fit lines are approximately parallel to each other indicating that the path loss exponent is the same at the two heights for both simulation and measurement as shown in Table 4. It is also seen that the fit line for the case of Tx antenna height $1.2 \mathrm{~m}$ is higher by $4 \mathrm{~dB}$ than the fit line for the $2.5 \mathrm{~m}$ Tx antenna height for both simulation and measurement results. This difference is also indicated in the mean values of the received power as shown in Table 4. These differences are due to two factors. The first is the effect of the radiation patterns of the Tx and $\mathrm{Rx}$ antennas which becomes more effective when the antenna heights are far from equal. The pattern of each antenna may be given by the normalized function $F(\theta)=\sin (\theta)$, where $\theta$ is measured from the vertical axis of the antenna as shown in Figure 5a. The second factor is that the direct-path ray travels a longer distance when increasing the Tx height (i.e. $\bar{d}$ is longer than $d$ ). This factor has a higher effect in regions near to the Tx (while $\overline{d_{1}} \cong d_{1}$ in far regions) see Figure 5a. 
Table 4. Calculated Parameters of the Received Power Results for Different Cases of Tx Antenna Height and Orientations

\begin{tabular}{ccccccccc}
\hline $\begin{array}{c}\text { Tx } \\
\text { Height }(\mathrm{m})\end{array}$ & $\begin{array}{c}\text { Rx } \\
\text { Height }(\mathrm{m})\end{array}$ & $\begin{array}{c}\text { Antenna } \\
\text { Orientation }\end{array}$ & $\mathrm{n}$ & $\begin{array}{c}\text { Measurements } \\
\text { RMSE } \\
(\mathrm{dBm})\end{array}$ & $\begin{array}{c}\text { Mean } \\
(\mathrm{dBm})\end{array}$ & $\mathrm{n}$ & $\begin{array}{c}\text { Simulation } \\
\text { RMSE } \\
(\mathrm{dBm})\end{array}$ & $\begin{array}{c}\text { Mean } \\
(\mathrm{dBm})\end{array}$ \\
\hline 1.2 & 1.2 & $\mathrm{~V}$ & 1.43 & 3.56 & -46.7 & 1.51 & 3.67 & -46.96 \\
1.2 & 1.2 & $\mathrm{H}$ & 1.23 & 4.5 & -44.45 & 1.15 & 3.9 & -43.75 \\
2.5 & 1.2 & $\mathrm{~V}$ & 1.33 & 2.24 & -49.27 & 1.51 & 2.79 & -50.47 \\
2.5 & 1.2 & $\mathrm{H}$ & 1.54 & 3.7 & -45.32 & 1.63 & 3.3 & -44.42 \\
\hline
\end{tabular}

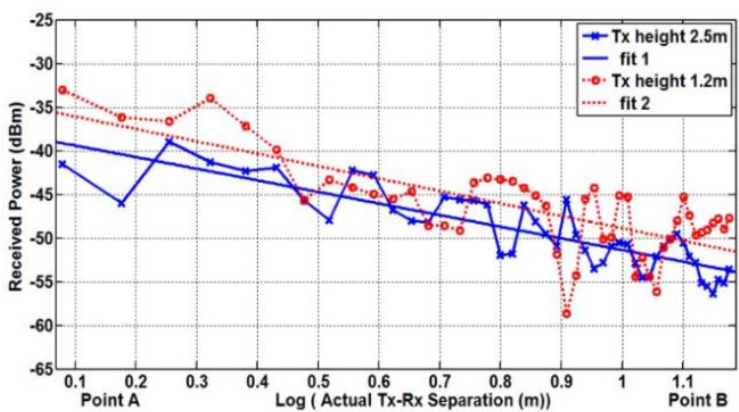

(a)

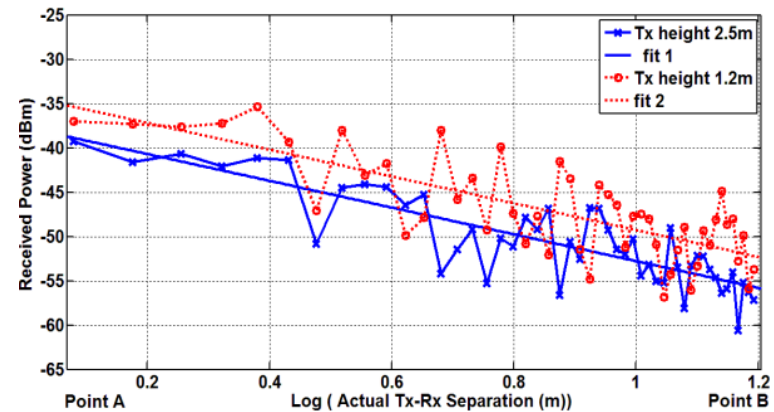

(b)

Figure 4. Variation of the received power along the Tx-Rx path, for vertically oriented antennas at the height of $1.2 \mathrm{~m}$ and $2.5 \mathrm{~m}$; (a) Simulation, (b) Measurements

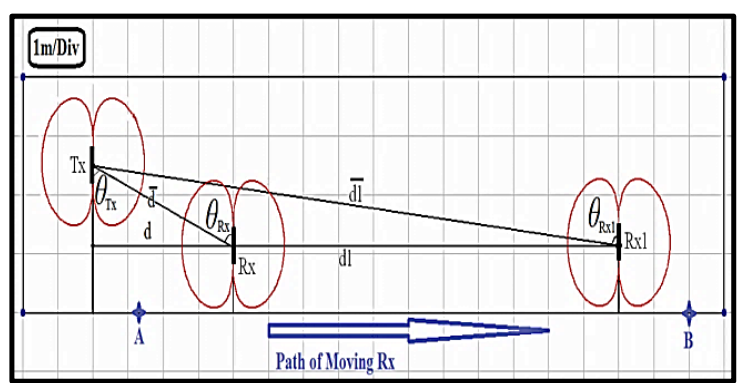

(a)

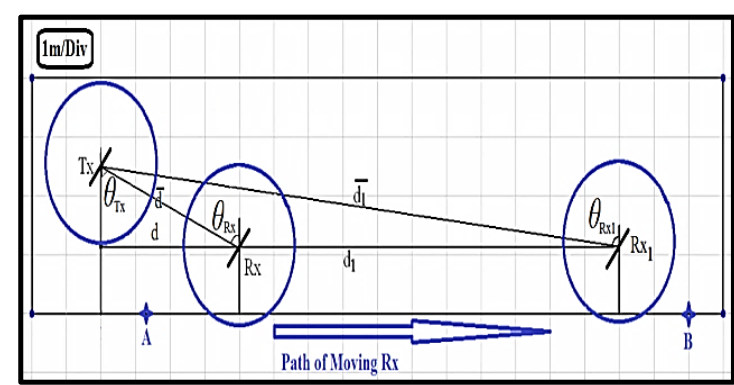

(b)

Figure 5. Orientations of Tx and Rx antennas; (a) vertically oriented, (b) horizontally oriented

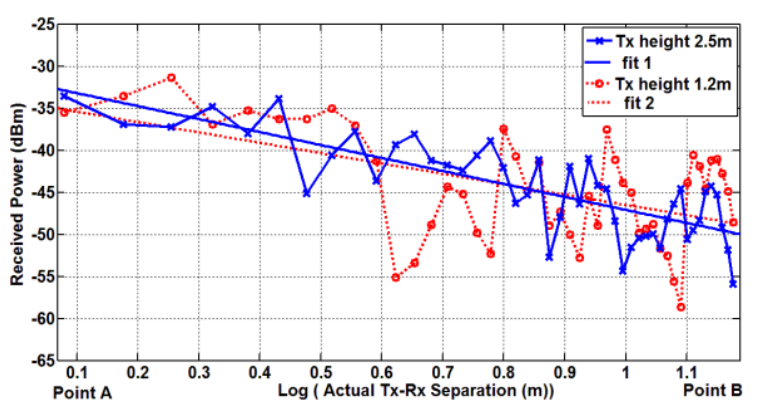

(a)

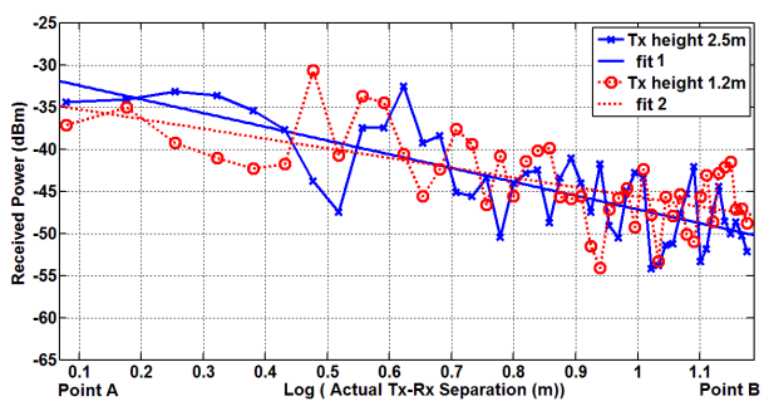

(b)

Figure 6. Variations of the received power along the Tx-Rx path, the antennas were horizontally oriented at heights of $1.2 \mathrm{~m}$ and $2.5 \mathrm{~m}$; (a) Simulation, (b) Measurement

\section{2) Horizontal Antenna Orientation}

Figure 6 shows plots of the received power obtained from the simulation and measurements respectively for the heights of Tx $1.2 \mathrm{~m}$ and $2.5 \mathrm{~m}$ and horizontal orientation of the antennas. The calculated 
parameters of the received power are listed in Table 4. Figure 6 shows that there is a difference in the slope of the fit lines. Only the second factor (mentioned above) has an effect on the received power see Figure $5 \mathrm{~b}$. This gives an indication about the small differences in the mean received power and RMSE values.

\subsection{Received Power for (OLOS) Cases}

The Obstructed Line of Sight (OLOS) path scenario was also investigated. The variation of the received power and path loss exponent at 24 test locations inside the building were determined. Six of these points have LOS rays while the remaining 18 points have OLOS rays. This situation is with respect to $\mathrm{Tx}$ position at point A see Figure 1. The test points were chosen to assess coverage at various rooms placed on the $1^{\text {st }}$ floor of the building. The Tx was located in the corridor at $1.2 \mathrm{~m}$ height.

The received power at any test point depends on the separation between Tx and Rx, and the number and type of walls between them. The variation of the received power is plotted in Figure 7. The results of test points were arranged according to their distances from the Tx in an ascending manner. The test points were classified (according to the number of walls that separate between the Tx and Rx) into 4 sets. These sets are unobstructed sets as well as sets obstructed by 1,2 and 3 walls respectively as shown in Figure 7 . The path loss exponent and RMSE values for each set of data are listed in Table 5. Figure 7 and Table 5 show that the path loss exponent has increased when the number of obstructing walls increased. The last set of data (for the case of three obstructing walls) comprised 5 test points. Thus, the estimated values of the path loss exponent may not be as accurate as that for the larger number of test points. However, the estimated values of the path loss exponent were between 2.17 and 2.37 for the simulations and between 2.26 and 2.55 for the measurements for the cases of one to three obstructing walls. This indicates that the obstructing wall effect is exhibited as a slight increase in the path loss exponent as well as an added amount of loss. In a former paper, it was shown that the added path loss due to the obstructing walls is about $3.5 \mathrm{~dB} /$ wall [11].

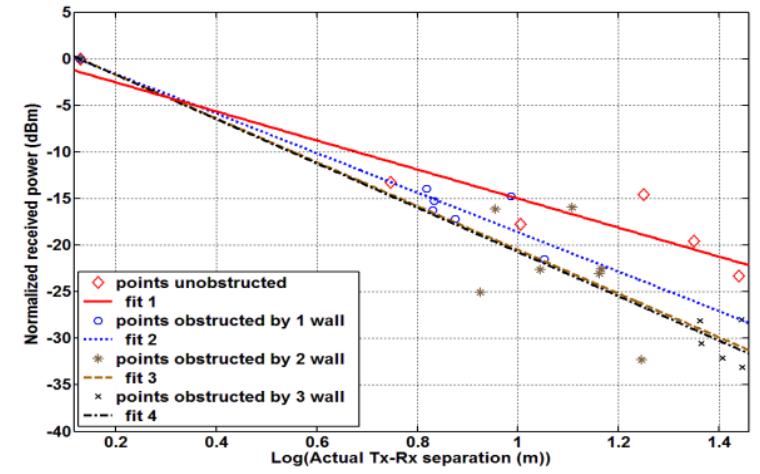

(a)

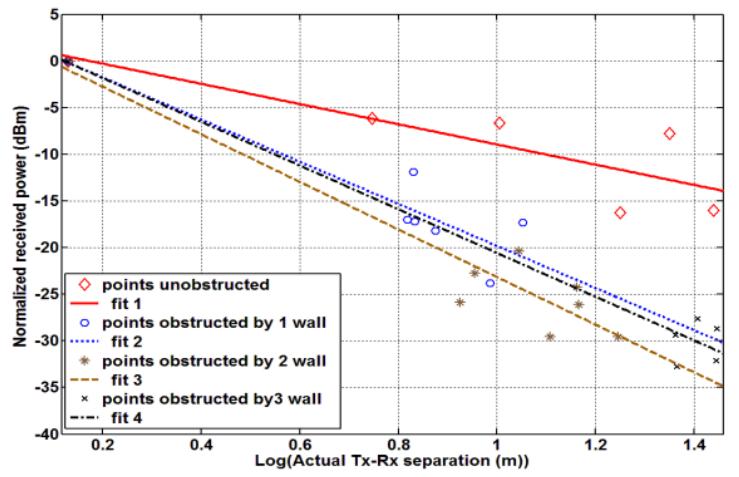

(b)

Figure 7. Variation of the received power with distance for; actual data and fitted lines for the;

(a) Simulation, and (b) Measurement

Table (5). Calculated Parameters of the Received Power for Each Set of Data, for Simulation and Measurements

\begin{tabular}{cccccc}
\hline $\begin{array}{c}\text { Number of } \\
\text { walls }\end{array}$ & $\begin{array}{c}\text { Number of test } \\
\text { points }\end{array}$ & \multicolumn{2}{c}{ Simulation } & \multicolumn{2}{c}{ Measurement } \\
RMSE & $n$ & $\begin{array}{c}\text { RMSE } \\
(\mathrm{dB})\end{array}$ \\
\hline 0 & 6 & 1.5 & 3.3 & 1.1 & 3.7 \\
1 & 6 & 2.17 & 1.97 & 2.26 & 3.2 \\
2 & 7 & 2.35 & 4.8 & 2.55 & 3.2 \\
3 & 5 & 2.37 & 2.2 & 2.34 & 2.5 \\
\hline
\end{tabular}

\section{COMPARISONS WITH OTHER WORKS}

Table 6 shows a comparison of the obtained path loss exponents in this work with those that have been reported in recent works. The cases that have similar environments to those investigated in this work are considered in the comparison. The obtained results in this work are comparable to those found for the LOS scenarios. However, the estimated path loss exponents for the OLOS cases in $[12,15,16,19]$ are slightly higher. This can be related to the type and number of walls that sperate between Tx and Rx. Also, this can be 
related to the existence of metallic obstacles as in $[12,15,16]$. Whereas in [19] the rooms are busy by humans this leads to more consumption of electromagnetic field and higher path loss exponent.

\begin{tabular}{clll} 
Table 6. Comparison of Path Loss Exponent with Recent Works \\
\cline { 2 - 4 } & \multicolumn{3}{l}{ Ferq. } \\
Environment / Ref. & $\mathrm{n}$ & Case \\
\hline This work (corridor) & 2.45 & $1.15-1.63$ & LOS \\
This work (corridor+rooms) & 2.45 & $2.14-2.55$ & OLOS \\
Rooms [12] & 2.5 & 1.56 & LOS \\
Corridor [13] & 2.4 & $1.57-1.68$ & LOS \\
Hallway [14] & 2.45 & 1.3 & LOS \\
Corridor [15] & 2.6 & 1.27 & LOS \\
Labrotaory [16] & 2.35 & 1.95 & LOS \\
Corridor [17] & $2 . .48$ & $1.19-1.48$ & LOS \\
Conference room [18] & 2.45 & $1.2-1.7$ & LOS \\
Corridor+ Open space [19] & 2.45 & $1.73-1.92$ & LOS \\
Obstructed Rooms [12] & 2.5 & $2.9-3.08$ & OLOS \\
Rooms+ Hallway [14] & 2.45 & 2.5 & OLOS \\
Obstructed Rooms[15] & 2.6 & 3.34 & OLOS \\
Obstructed Labrotaory [16] & 2.35 & 2.8 & OLOS \\
Busy Rooms[19] & 2.45 & $2.67-3.29$ & OLOS \\
\hline
\end{tabular}

\section{CONCLUSIONS}

It can be concluded from the performed simulations and measurements that the path loss exponent (n) in WLAN systems depends on the nature of the path between Tx and Rx (either LOS path or OLOS path). Moreover, it depends on the environment (corridor, rooms, type of walls, ....). It was found that the value of the path loss exponent is less than 2 (1.15-1.63) for LOS path in the corridor and larger than 2 for OLOS path. Therefore, the in-building environment slightly enhances the LOS propagation compared to the freespace propagation that is characterized by an exponent of 2 . This can be attributed to enhancements due to reflections from walls, ceilings, and floors. However, OLOS scenarios are worse than free space ones. Orientations, heights, and positions of the $\mathrm{Tx}$ and $\mathrm{Rx}$ antennas must be taken into consideration when installing a WLAN system.

\section{REFERENCES}

[1] T. S. Rappaport, "Wireless Communications Principles and Practice", 2nd Edition, Prentice Hall PTR. 2002.

[2] J. D. Parsons, "The Mobile Radio Propagation Channel", $2^{\text {nd }}$ Edition, John Wiley and Sons, 2000.

[3] K. R. Schaubach, N. J. Davis, and T. S. Rappaport, "A Ray Tracing Method for Predicting Path Loss and Delay Spread in Microcellular Environments", IEEE Transactions on Vehicular Technology, Vol. 2, pp. 932-935,1992.

[4] H. Salaheddin, et al., "Empirical propagation performance evaluation of LoRa for indoor environment", 15th IEEE conference on industrial informatics, pp: 26-31, July. 2017.

[5] K. H. Sayidmarie and Y. E. M. Ali, "Characterization of indoor radiowave propagation at university buildings", Asia-Pacific Radio Science Conference AP-RSC04, 24-27 Aug. 2004, Qing Dao, China.

[6] D. Dres, et al., "Building penetration measurements for 2.4 GHz broadcasting CDMA system", IEEE Vehicular Technology Conference, pp. 1982-1987, 1999.

[7] S.Y. Seidel and T. S. Rappaport, " 914 MHz Path Loss Prediction Models for Indoor Wireless Communications in Multifloored Buildings", IEEE Transaction on Antennas and Propagation, Vol. 40, No. 2, pp. 207-217, Feb. 1992.

[8] O. Oni and F. Idachaba, "Review of Selected Wireless System Path Loss Prediction Models and Its Adaption to Indoor Propagation Environments", International conference of Engineers and Computers Scientists, Vol. 2, Hong Kong, 15-17 March 2017.

[9] Z. Youmni, "Optimization of Indoor Radio Coverage" IEEE Middle East and North Africa Communications Conference, 18-20 April 2018.

[10] H. A. Obiedat, et al, "An Indoor Path Loss Prediction Model Using Wall Correction Factor for Wireless Local Area Network and 5G Indoor Networks", Journal of Radio Science, Vol. 53, Issue 4, pp. 544-564, April 2018.

[11] Khalil H. Sayidmarie, Abdullah H. Aboud, and Mohammed S. Salim, "Estimation of Wall Penetration Loss for Indoor WLAN Systems", International Conference on Sciences of Electronics Technologies of Informations and Telecommunications, SETIT12, 21-24 March 2012, Tunisia.

[12] P. Nobles, and F. Halsall, "Delay Spread and Received Power Measurements within a Building at 2 GHz, 5 GHz and $17 \mathrm{GHz}$ ", 10th international IEEE Conference on Antennas and Propagation, pp. 2319-2324, 14-17 April 1997.

[13] D.Tummala, "Indoor Propagation Modeling at $2.4 \mathrm{GHz}$ for IEEE 802.11 Networks", MSc. dissertation, Department of Engineering Technology, North Texas University, USA, 2005. 
[14] D. Lu, and D. Rutledge, "Investigation of Indoor Radio Channels from 2.4GHz to 24GHz", IEEE International Symposium on Antennas and Propagation, Vol. 2, PP. 134-137, USA, 22-27 June 2003.

[15] A. Zyoud, H. M. Habaebi and R. Islam, "Parameterized Indoor Propagation Model for Mobile Communication Links", Microwave and Optical Technology Letters, Vol. 58, Issue 2, pp. 823-826, Apr. 2016.

[16] G. Yi-Liu, et al, "Path Loss Measurements of Indoor LTE System for the Internet of Things", Journal of Applied Science, Vol. 7, Issue 6, pp. 1-8, May 2017.

[17] Z. Ganev, "Indoor Propagation of Signals Between Wireless Sensor Nodes", $15^{\text {th }}$ International Conference on Electrical Machines, Drivers and Power Systems, Bulgaria, pp. 467-470, June 2017.

[18] F. Heereman, "Path loss model and prediction of range, power and throughput for $802.11 \mathrm{n}$ in large conference rooms", International Journal of Electronics and Communications, Vol. 66, Issue 7, pp. 561-568, July 2012.

[19] K. H. Rath, et al, "Realistic Indoor Path Loss Modeling for Regular WiFi Operations in India", $23^{\text {rd }}$ international IEEE conference on Communication, India, pp 1-6, Vol. 1, Mar. 2017.

\section{BIOGRAPHIES OF AUTHORS}

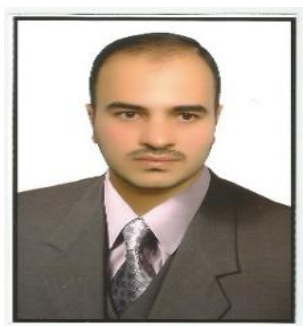

Mohammed Sameer Salim was born in Mosul / Iraq at 1987. He completed his MSc study in communication Engineering at the college of electronic engineering / university of Mosul (2013). He is now working as assistant lecturer at the Communication Engineering Dept. / College of Electonic Engineering/ Ninevah University. His reserch interests include antennas and wave propagation.

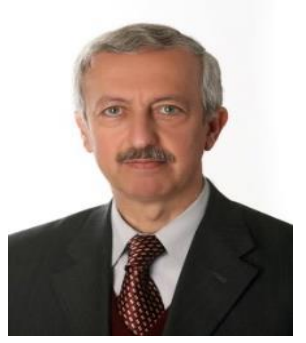

Prof Khalil H. Sayidmarie received the B.Sc. degree with first class honor in Electronic \& Communication Eng. from Mosul University, Iraq, in 1976, and Ph.D. Degree in Antennas \& Propagation from Sheffield University/ U.K. in 1981. Then he joined the College of Engineering at Mosul University in 1983, and was promoted to full professor on 1992. He worked as the head of the electrical engineering department for 9 years. He was a cofounder of the College of Electronic Engineering at Mosul University. He has been Professor of communication engineering at that college. Sayidmarie served as Prof. of communication engineering at the College of Engineering/ University of Amman Al-Ahliyya/ Jordan from Oct 2006 to Sept. 2009. He served as the Dean of that college from Sept 2008 to Sept 2009. He has being Prof of communication engineering at the college of electronic engineering/ Ninevah University since July 2002. He was the recepient of a 6-month research scholarship from the australian Endeavour in 2007 and a 4-month Endeavour Executive Fellowship in 2018, both spent at the ITEE/Univeristy of Queensland/ Australia. He was a visiting profesor for one month to Bradford University. He was awarded the Science Distinction Medal from the Ministry of Higher Education and Scientific Research/Iraq for his achievements in the field of Electrical Engineering, May 2013. Sayidmarie research interests cover antennas, propagation, and microwaves, where he has published more than 120 papers in refereed journals and conferences, and has supervised $38 \mathrm{MSc}$ and $\mathrm{PhD}$ theses.

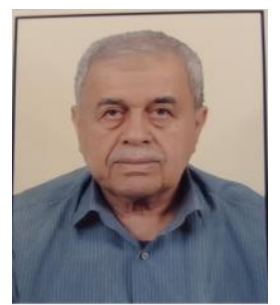

A. H. Aboud received the B.Sc, M.Sc and Ph.D degree in Electronics and Communication Engineering from University of Mosul Iraq in 1975, 1989, and 2007 respectively. He worked at the Electrical Engineering Dept./Mosul University since 1976. He served as head of Communications Engineering Depart./College of Electronics Engineering at Ninevah University for 4 years, then he retired on 2017. His research interests include the field of antenna arrays and propagation. 